\title{
THE ROTATING CONE FLASH PYROLYSIS REACTOR
}

\author{
B.M. Wagenaar \\ J.A.M. Kuipers, W. Prins, W.P.M. van Swaaij \\ Department of Chemical Engineering \\ University of Twente \\ Enschede, The Netherlands.
}

\begin{abstract}
The velocity of nearly spherical mono-sized PVC powder in a cold-flow rotating cone reactor (top angle $\pi / 3 \mathrm{rad}$, height $0.43 \mathrm{~m}$ ) was measured under variation of the particle diameter $(140-780 \mu \mathrm{m})$ and the cone rotational speed (up to $1800 \mathrm{rpm}$ ). Derived residence times for these particles vary from 0.05 to 0.3 second. The gas velocity distribution near the cone wall appeared to have a considerable influence on the velocity of particles smaller than $200 \mu \mathrm{m}$. Next to the experimental work a mathematical model is presented, using a single-particle description and a gas-flow description near the wall according to the universal velocity profile [1]. The conversion of biomass can be calculated by combining the hydrodynamic model together with a proper heat transfer and pyrolysis model. Particles smaller than $200 \mu \mathrm{m}$ may pyrolyse completely in the present rotating cone flash pyrolysis reactor.
\end{abstract}

\section{INTRODUCTION}

The rotating cone reactor is a novel reactor type for flash pyrolysis of biomass with negligible char formation, in which rapid heating and a short residence time of the solids can be realised. Particles fed into the reactor first enter an impeller which is mounted in the base of the heated cone. After leaving the impeller the particles flow outwards over the conical surface and experience a high heat transfer rate due to their small distance from the heated surface, see figure 1. Biomass materials like wood, rice husks or even olive 
stones can be pulverised and fed to the rotating cone reactor. Flash heating of the biomass will suppress coke forming cracking reactions. Since no carrier gas is needed (cost reducing) the pyrolysis products will be formed at high concentrations. If additional thermal quenching of the gas outlet flow is applied the amount of secondary tar decomposition reactions can be suppressed.

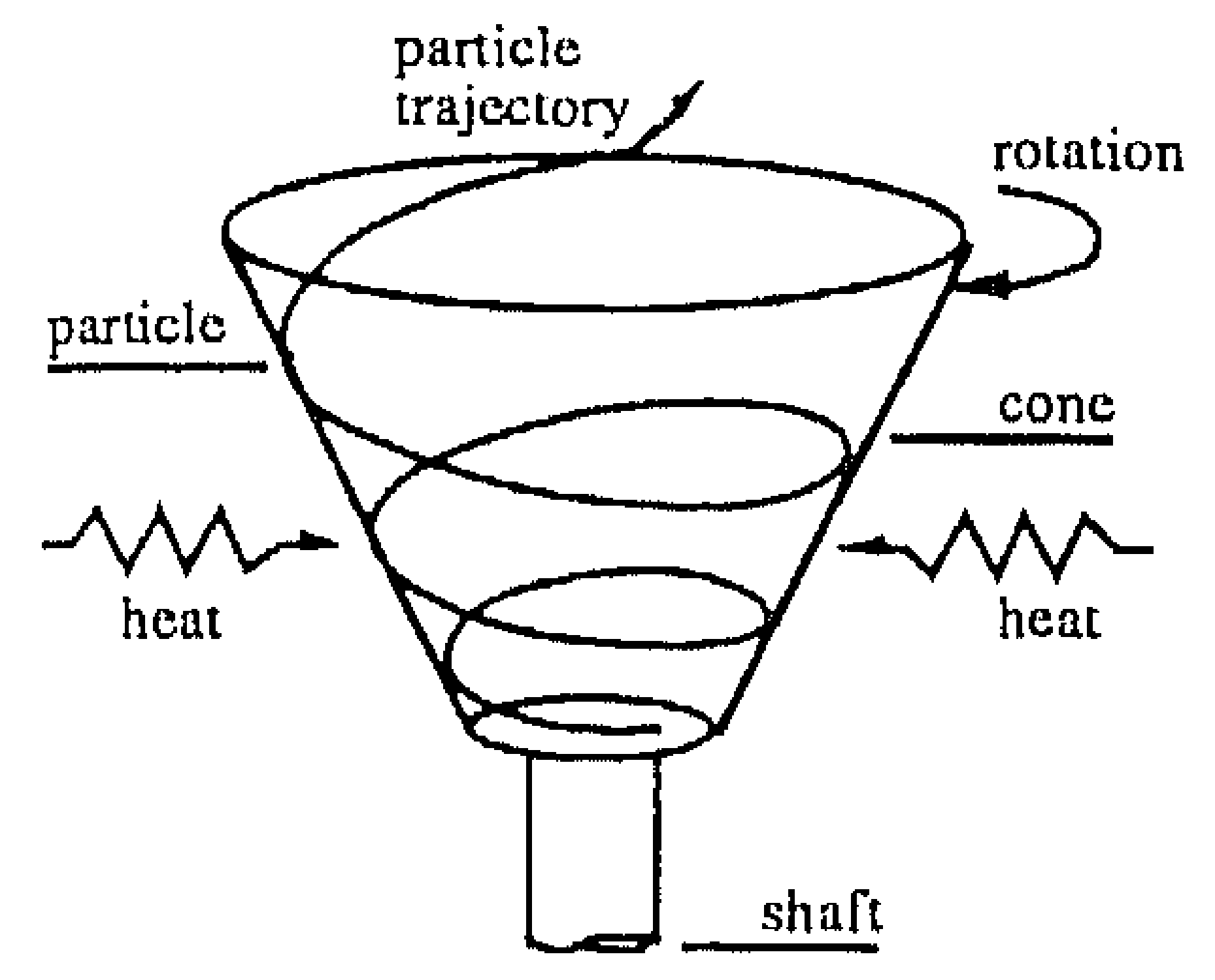

Figure 1. The cone.

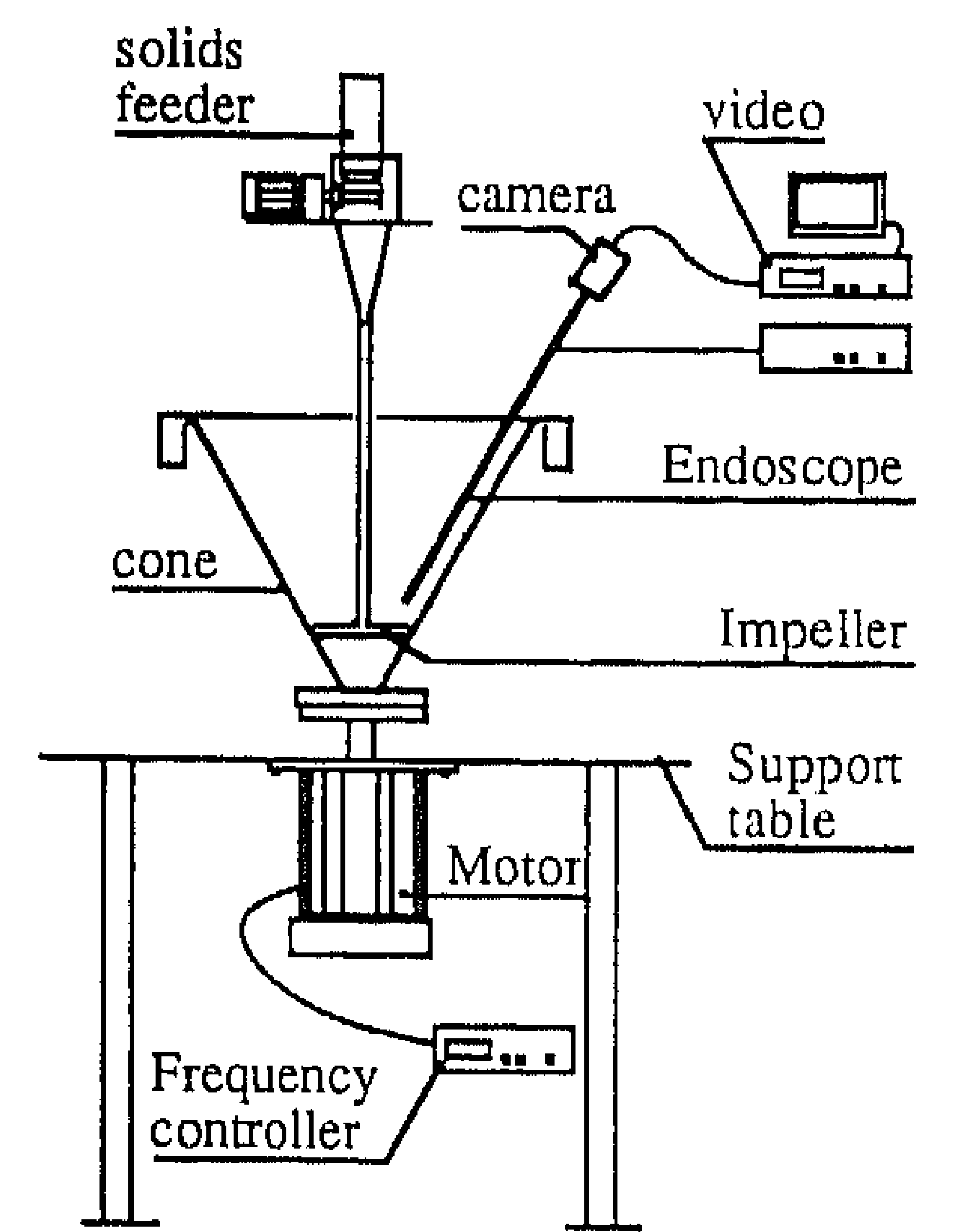

Figure 2. The experimental set-up.

\section{EXPERIMENTAL}

The present cone has a height of $0.435 \mathrm{~m}$ and a top angle of $\pi / 3$ radians. An impeller of $0.142 \mathrm{~m}$ diameter is mounted in the base of the cone. The motion of the particles along the cone wall was recorded with a video camera. PVC particles are used as a model material because of their bright white colour which gives a maximum photographical contrast on the black cone wall. The video camera is mounted on an endoscope which can be moved parallel to the cone wall so that a constant image magnification is obtained. At a shutter speed of $1 \mathrm{~ms}$, the particle movement can be seen as streaks of a few mm length. This length is directly proportional to the local particle velocity. PVC powder has a density of $1100 \mathrm{~kg} \cdot \mathrm{m}^{-3}$ which is about twice the of density of biomass. The gas phase velocity is measured with a hot wire anemometer [2] positioned at $3 \mathrm{~mm}$ distance from the cone wall. 


\section{THE REACTOR HYDRODYNAMICS}

The mathematical model which describes the particle trajectories and velocities consists of two parts: a single-particle model and a hydrodynamic model which describes the flow of the gas phase. The particle motion is calculated from a force balance which is applied to a particle moving in free flight between two successive wall collisions. Collisions between particle and the cone wall are assumed to be elastic. Experimental determination of the macroscopic flow behaviour of the gas phase inside the rotating cone is performed with a hot wire anemometer. The flow in the turbulent boundary layer along the cone wall can be described by the "law of the wall" [1], and is coupled to the macroscopic flow by assuming smoothness of the velocity
profile and its first derivative.

Single particle momentum equation

The force balance on a particle yields:

$$
m_{p} \cdot \frac{d \underline{v}}{d t}=\underline{F}_{d}+\underline{F}_{g}
$$

with

$$
\begin{gathered}
\underline{F}_{g}=m_{p} \cdot g \\
\underline{F}_{d}=C_{d} \cdot \frac{\pi}{4} \cdot d_{p}^{2} \cdot \frac{1}{2} \cdot \rho_{f} \cdot \underline{v}_{f}-\underline{v}_{p} \mid \cdot\left(\underline{v}_{f}-v_{p}\right)
\end{gathered}
$$

The elastic collision of a particle with the cone wall requires that:

$$
\underline{\mathrm{v}}_{\mathrm{p}, \text { after collision }}=\left(\underline{1-\underline{\mathrm{nn}})} \cdot \underline{\mathrm{v}}_{\mathrm{p}}\right. \text {, before collision }
$$

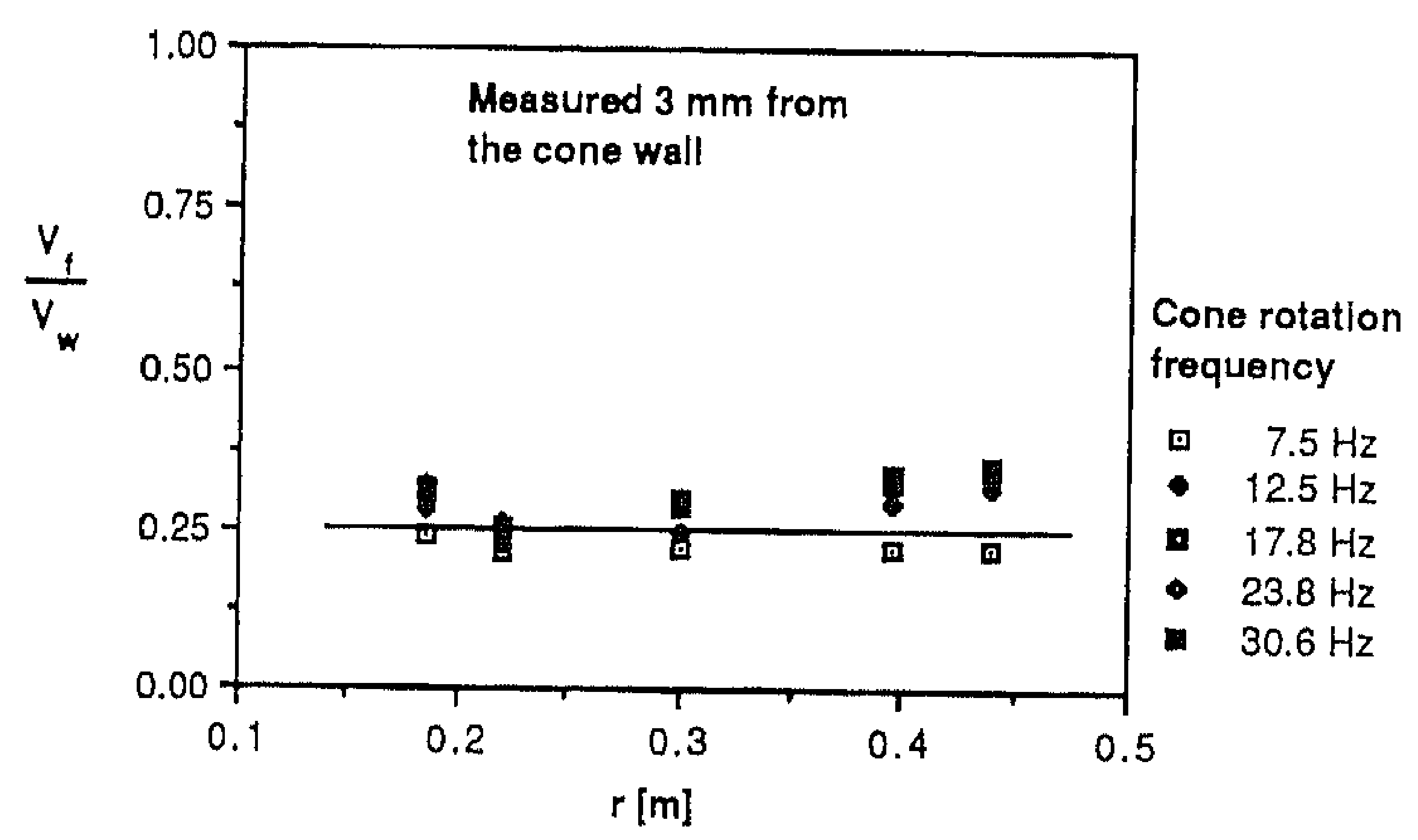

Figure 3 . The ratio of the gas phase and wall velocity versus the radial coordinate. 


\section{Gas phase description}

Video recordings of an injection of smoke into the rotating cone showed that the gas cloud in the core of the cone had an angular speed of roughly 1/4 of that of the rotating cone. These preliminary observations have been verified by measuring the gas phase velocity with a hot wire anemometer of which results are presented in figure 3 . The velocities where measured at different positions along the wall and different cone rotational speeds.

When applying the universal velocity profile [1], two other layers have to be considered, the logarithmic layer (Eq. 7) and the surface-roughness layer (Eq. 8). A viscous sub-layer is absent because of the wall roughness caused by the eccentricity of the cone. (The deviation in circularity of the cone's crosssection is $1 \mathrm{~mm}$ ). Eq. 9 represents the no-slip condition of the gas phase at the cone wall.

The velocity profile of the gas phase is described by:

$$
\underline{v}_{\mathrm{f}}=\mathrm{v}_{\mathrm{f}} \cdot \mathrm{e}_{\varphi}
$$

and consists of three parts, see also figure 4 :

$$
\mathrm{R}<\mathrm{R}_{\mathrm{w}^{-}}-\delta: \quad \mathrm{v}_{\mathrm{f}}=\frac{1}{4} \cdot \omega \cdot \mathrm{R}
$$

$\mathrm{R}_{\mathrm{W}}-\delta<\mathrm{R}<\mathrm{R}_{\mathrm{W}}-\mathrm{h}:$

$$
v_{f}=\omega \cdot R_{w}-\frac{1}{4} \cdot \omega \cdot \delta \cdot \ln \frac{R_{w}-R}{(h / 30)}
$$

$h / 30$ is derived from measurements [1] and is called the roughness length.

$$
\mathrm{R}_{\mathrm{w}}-\mathrm{h}<\mathrm{R}<\mathrm{R}_{\mathrm{w}}: \quad \mathrm{v}_{\mathrm{f}}=\omega \cdot \mathrm{R}_{\mathrm{w}}-\frac{1}{4} \cdot \omega \cdot \delta \cdot \frac{\mathrm{R}_{\mathrm{w}}-\mathrm{R}}{\mathrm{h}} \cdot \ln 30
$$

The parameter $\delta$ couples the macroscopic flow described by Eq. 6 , with the flow in the turbulent boundary layer Eq. 7 and is therefore given by:

$$
\frac{1}{3} \cdot \delta \cdot(\ln \delta+10)=\mathrm{R}_{\mathrm{w}}
$$

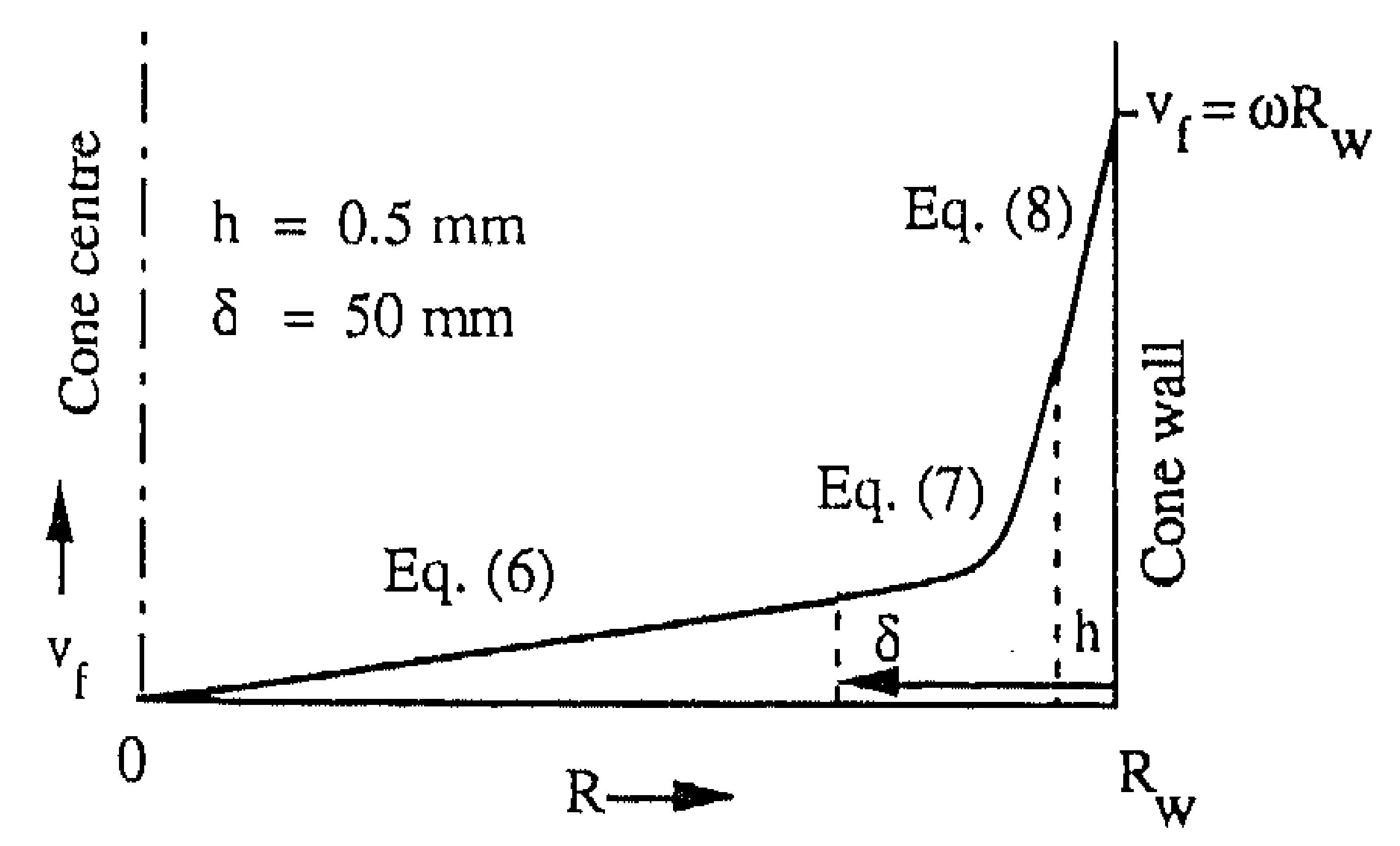

Figure 4. Assumed radial profile of the angular gas velocity. 
The local particle velocity $\underline{v}_{p}(r)$ can be measured, and calculated from the hydrodynamic model described by eqs. 1-9. The particle residence time in the cone is calculated by integrating the reciprocal radial velocity component along the radial co-ordinate.

$$
\tau_{p}=\int_{r_{0}}^{r_{1}} \frac{d r}{v_{p, r}}
$$

\section{RESULTS}

Particle velocity measurements have been carried out for various different particle diameters and cone rotational speeds. From these measurements, the residence time of the particles versus the cone rotational speed is derived by using Eq. 10. The results are presented in figure 5. As expected the particle residence time decreases rapidly with an increasing cone rotational frequency because of increased velocities of the particles. Figure 5 further indicates that for particles smaller than $200 \mu \mathrm{m}$ the viscous force becomes important with respect to the particle mass inertia. Particles larger than $400 \mu \mathrm{m}$ seem to be unaffected by the viscous forces and the residence times of particles with increasing diameter approach an asymptotic solution given by the solid curve in figure 5. In addition, calculations based on the theory outlined above have been carried out for conditions corresponding to the experimental set-up. In figure 6 these results of the calculations are compared with the experimental results. As evident from figure 6 the agreement between the model predictions and the experimental results is reasonable.

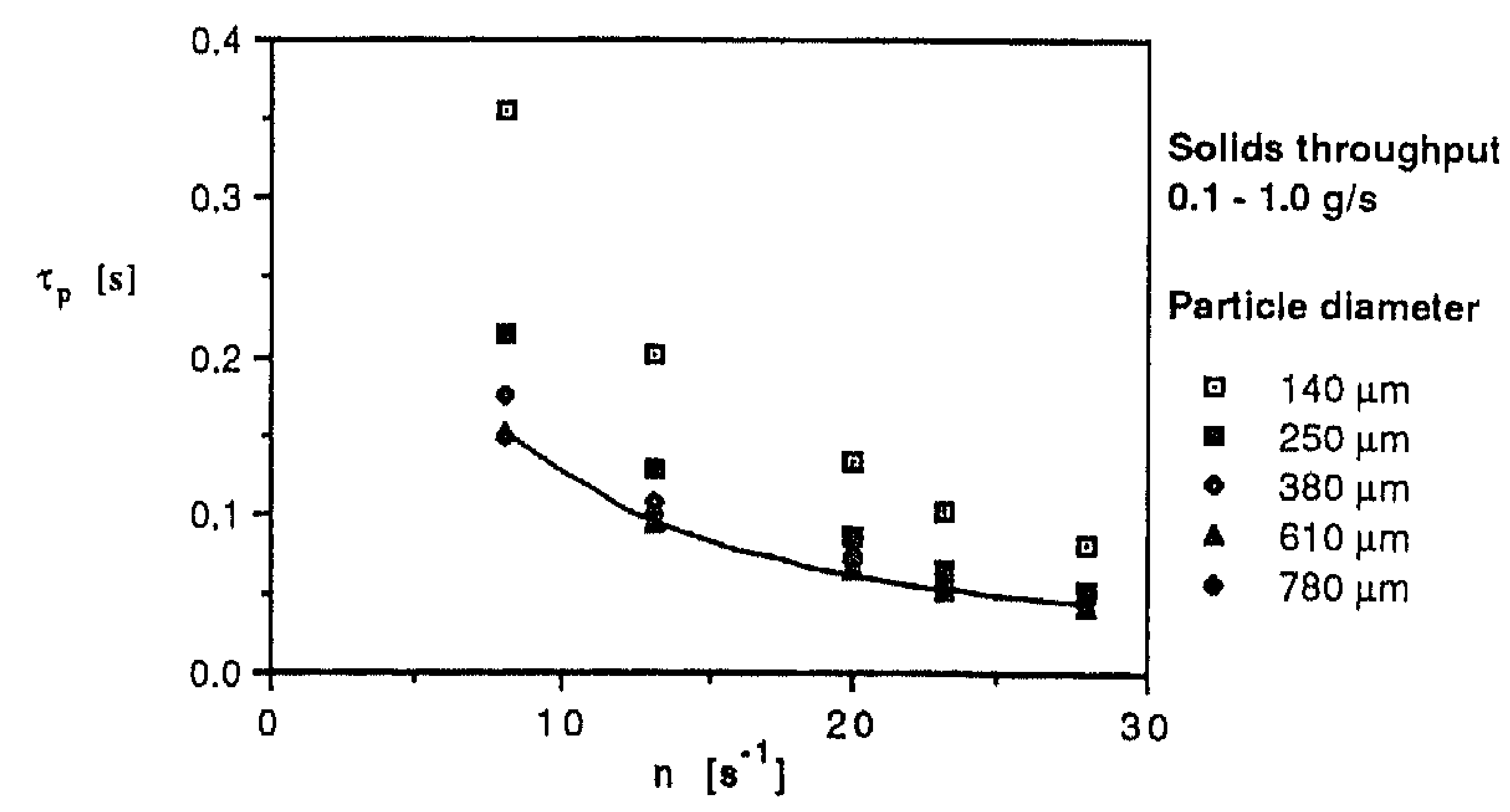

Figure 5. The particle residence time versus the cone rotational frequency. 


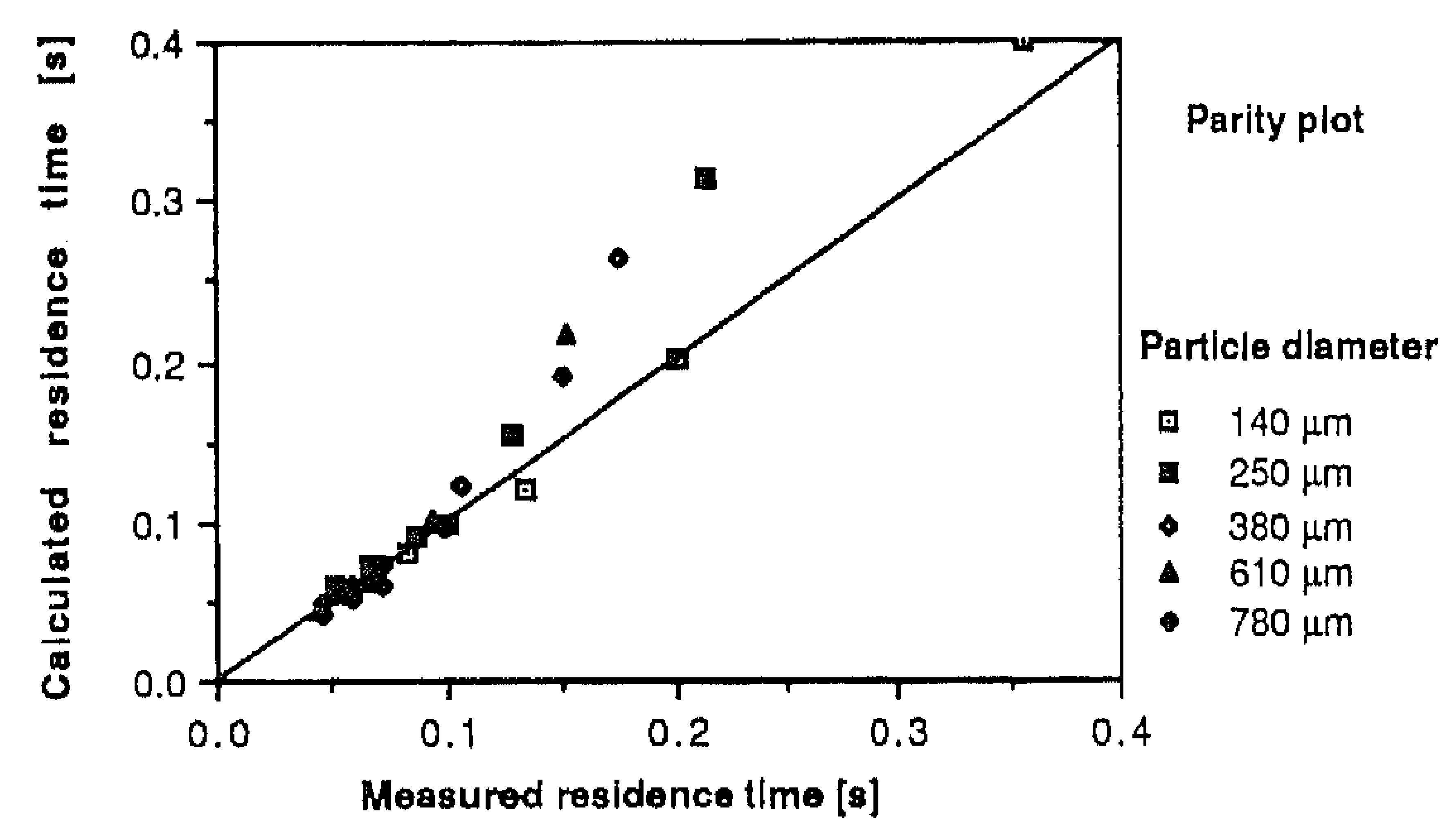

Figure 6. The calculated particle residence time versus the measured particle residence time.

\section{HEAT TRANSFER TO THE PARTICLES}

If particles are introduced with a temperature different from that of the reactor, heat exchange between the particles and the gas phase near the cone wall will occur. The gas-to-particle heat transfer coefficient can be derived from the correlation of Ranz and Marshall [3] for stationary particles in a flowing fluid. This correlation is adopted to calculate the local value of the particle heat transfer coefficient.

$$
\mathrm{Nu}_{\mathrm{p}}=2.0+0.6 \cdot \operatorname{Re}_{\mathrm{p}}^{0.5} \cdot \mathrm{Pr}^{0.33}
$$

The slip velocity in the particle Reynolds number can be calculated from the hydrodynamic model.

$$
\operatorname{Re}_{p}=\frac{\left|\underline{v}_{p}-\underline{v}_{f}\right| \cdot d_{p}}{v_{f}}
$$

The time averaged Nusselt number is given by;

$$
\overline{N u}_{p}=\frac{1}{\tau} \cdot \int_{0}^{\tau} N u_{p} \cdot d t
$$

If the variance of the time dependent Nusselt number is small compared to the time averaged Nusselt number, the Nusselt number can be regarded as a constant with only a small superimposed fluctuation. A biomass particle undergoing pyrolysis is coupled to its surroundings by the (time averaged) 
Nusselt number and the particle residence time. The advantage of using the time averaged Nusselt number is that the chemical conversion process can be decoupled from the reactor hydrodynamics, and studied independently. Values of $\mathrm{Nu}_{\mathrm{p}}$, presented in figure 7 are used for calculations with the pyrolysis model described hereafter.

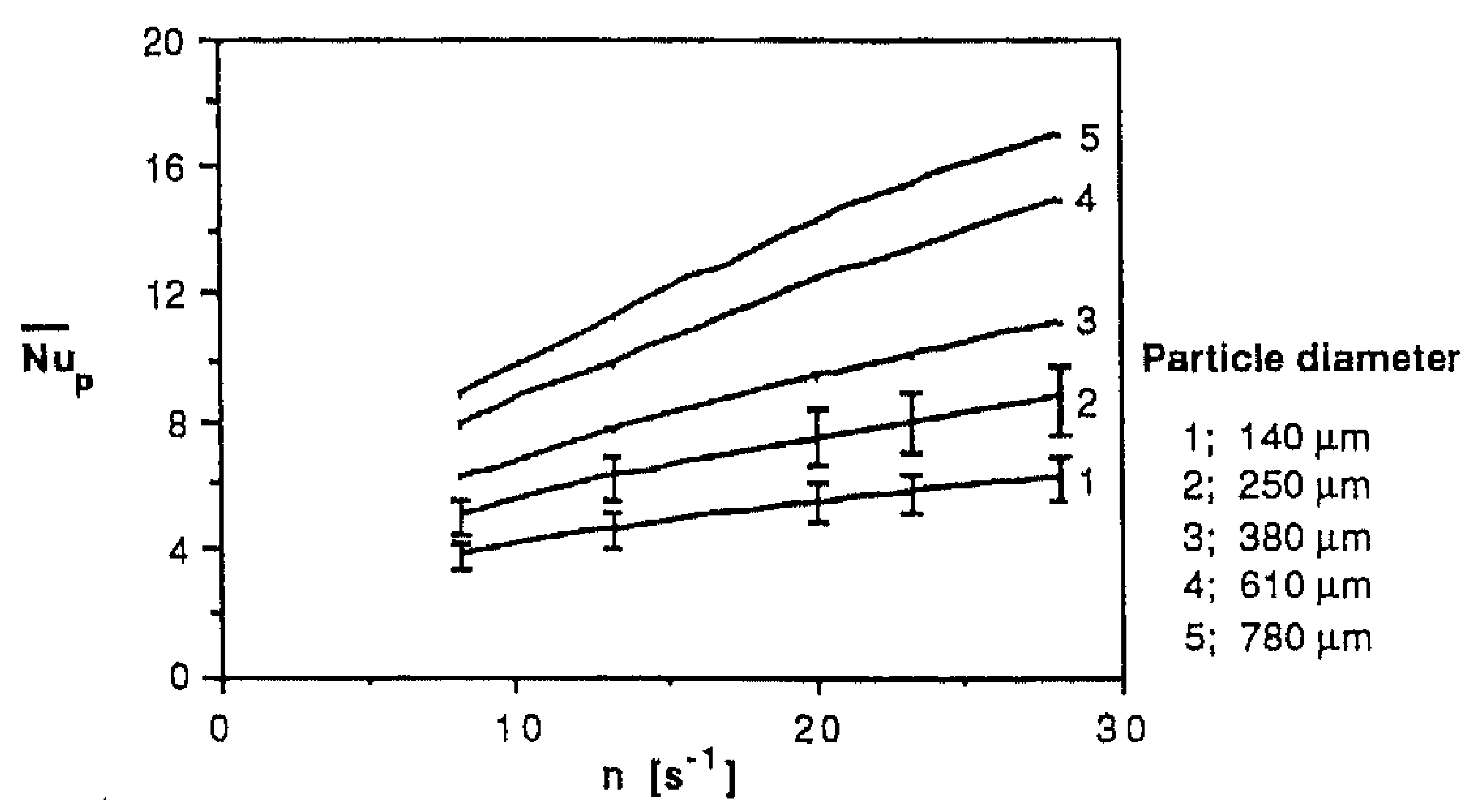

Figure 7. The time-averaged Nusselt number at different cone rotational frequencies. Variances are given only for 140 and $250 \mu \mathrm{m}$ particles.

\section{THE FLASH PYROLYSIS OF WOOD}

If pyrolysis of a sawdust particle is considered, two separate regions can be distinguished. The first region is the interior part of the biomass particle where heat conduction and pyrolysis occurs. The second region is outside the particle and includes the reactor geometry. Coupling of both regions occurs at the particle surface and is mathematically described by boundary conditions.

The transient behaviour of a particle undergoing pyrolysis can be described by the mass and heat balance. The mass balance incorporates the chemical reaction kinetics in which 4 different species can be distinguished i.e. wood, char, tar and gas. Liden et al. [4] have suggested the decomposition path as described in figure 8 , and have assumed that all chemical decomposition reactions are of first order.

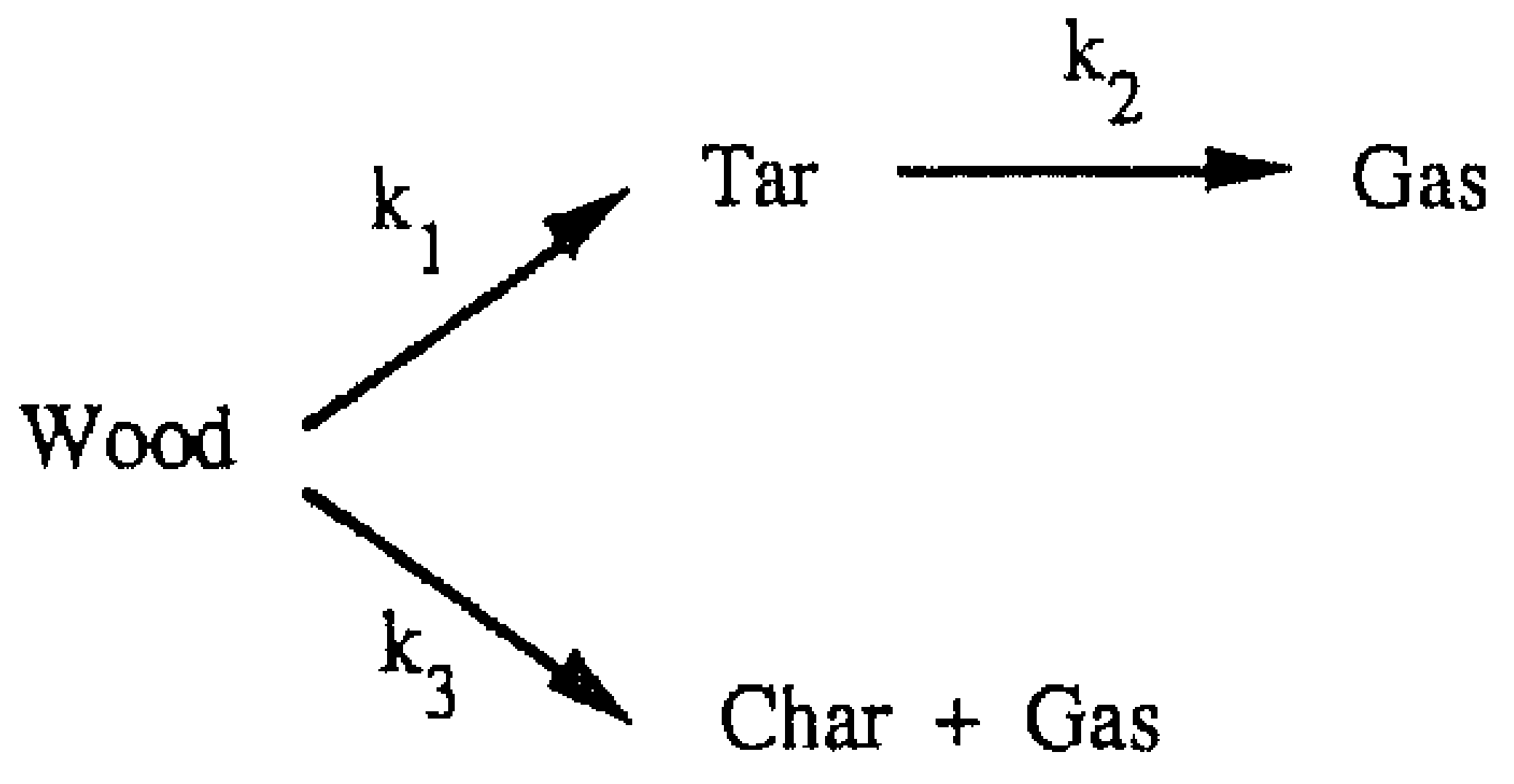

Figure 8. The wood decomposition path. 
The decomposition of wood occurs by way of the primary pyrolysis reactions 1 and 3, whereas the secondary tar decomposition is described by reaction 2 . If secondary tar decomposition reactions do not occur, for example due to a very short gas phase residence time, the tar yield will reach its maximum. This ultimate tar yield $\phi^{*}$ is defined as the weight fraction of the initial wood which is converted to tar.

$$
\begin{gathered}
\mathrm{k}_{1}=\phi^{*} \cdot \mathrm{k} \\
\mathrm{k}=\mathrm{k}_{1}+\mathrm{k}_{3}
\end{gathered}
$$

Where the primary pyrolysis reaction rate constant $\mathrm{k}$ is given by Kosstrin [5]:

$$
\mathrm{k}=10^{13} \cdot \mathrm{e}^{-\frac{183300}{\mathrm{RT}}}=\mathrm{k}_{1}+\mathrm{k}_{3}
$$

The secondary pyrolysis reaction rate constant $k_{2}$ is given by Liden et al. [4]:

$$
k_{2}=4.28 .10^{6} e^{-\frac{107500}{R T}}
$$

Together with the suggested value of $\phi^{*}=0.703$ the kinetics of the involved reactions is fully determined.

Hereafter, in Eqs. 18, 19, 20 and 21, the radius $r$ represents the radial position inside the particle.

$r=0, \quad$ the particle centre.

$r=r_{\mathrm{p}}, \quad$ the particle surface.

The mass balance of wood:

$$
\frac{\partial}{\partial t} C_{w}=-k \cdot C_{w}
$$

The energy balance of wood:

$$
\left(0.1 \mathrm{C}_{\mathrm{w}, 0}+0.9 \mathrm{C}_{\mathrm{w}}\right) \cdot \mathrm{C}_{\mathrm{p}, s} \cdot \frac{\partial \mathrm{T}_{\mathrm{s}}}{\partial \mathrm{t}}=\frac{1}{r^{2}} \frac{\partial}{\partial r} \lambda_{\mathrm{s}} r^{2} \frac{\partial \mathrm{T}_{\mathrm{s}}}{\partial r}-\mathrm{k} \cdot \mathrm{C}_{\mathrm{w}} \cdot \mathrm{H}_{\mathrm{r}}
$$

Assumed is no shrinkage of the wood particle and a 10 weight percent char yield, which explains the term $0.1 \mathrm{C}_{\mathrm{W}, 0}+0.9 \mathrm{C}_{\mathrm{W}}$. Because the composition of the solid structure changes with time, the heat capacity $C_{p, s}$ and the thermal conductivity $\lambda_{\mathrm{S}}$ represent an average of the values of wood and char taken from table 1. Deglise et al. [6] have published data concerning the heat effect of the pyrolysis reaction at different temperatures and wood moisture content. Values of the heat of pyrolysis range from -625 to $1970 \mathrm{~kJ}^{\mathrm{kg}}{ }^{-1}$ [6]. For the calculations a value of $500 \mathrm{~kJ}_{\mathrm{kg}} \mathrm{kg}^{-1}$ (endothermic) is used. 
The boundary condition at the particle centre expresses a zero heat conduction flux from the particle centre:

$$
\left.\left(-\lambda_{s} \cdot 4 \pi r^{2} \cdot \frac{\partial T_{s}}{\partial r}\right)\right|_{r=0}=0
$$

The boundary condition at the particle surface couples the heat transport by conduction inside the particle with the external heat transfer:

$$
-\left.\lambda_{\mathrm{s}} \cdot \frac{\partial \mathrm{T}_{\mathrm{s}}}{\partial r}\right|_{r=r_{\mathrm{p}}}=\alpha \cdot\left(\mathrm{T}_{\mathrm{s}} \mathrm{l}_{r=r_{\mathrm{p}}}-\mathrm{T}_{\mathrm{f}}\right)
$$

Here $\alpha$ represents the external heat transfer coefficient, through which the pyrolysis model is coupled to the particle heat transfer model. A gas phase temperature $T_{f}$ of $873 \mathrm{~K}$ was used. The time interval for which Eqs. 17 and 18 are solved is equal to the particle residence time and couples the pyrolysis model with the hydrodynamic model.

The initial conditions are:

$\mathrm{C}_{\mathrm{W}, 0}(\mathrm{t}=0)=500 \mathrm{~kg} \cdot \mathrm{m}^{-3}$

$\mathrm{T}_{\mathrm{S}, 0}(\mathrm{t}=0)=298 \mathrm{~K}$.

Eqs. 17, 18, 19 and 20 are solved by a finite-difference technique. The conversion $\xi$ due to pyrolysis of the particle can be defined in terms of the mass of wood evaporated relative to the initial wood mass as follows:

$$
\xi=1-\frac{3}{r_{\mathrm{p}}^{3} \cdot \mathrm{C}_{\mathrm{w}, 0}} \cdot \int_{0}^{r_{\mathrm{p}}} r^{2} \cdot \mathrm{C}_{\mathrm{w}}(r) \cdot \mathrm{d} r
$$

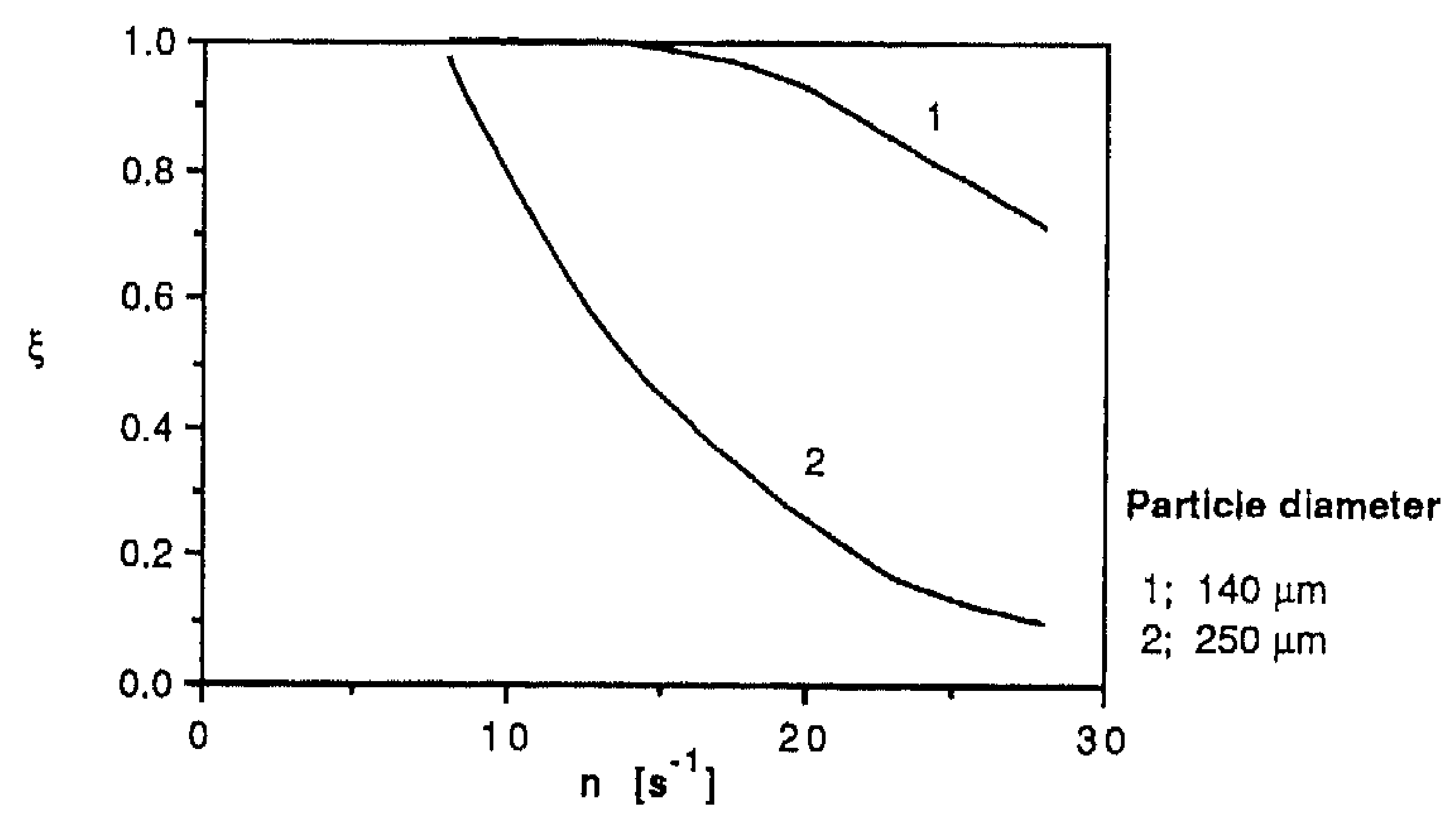

Figure 9. The calculated conversion versus the cone rotational speed for different particle diameters. 
Particles smaller than $140 \mu \mathrm{m}$ can be completely evaporated as can be seen in figure 9. If the cone rotational speed is larger than $10 \mathrm{~s}^{-1}$, the particle residence time in this particular reactor is too small to achieve a complete conversion of the $250 \mu \mathrm{m}$ sawdust particles. At cone rotational frequencies smaller than $5 \mathrm{~s}^{-1}$ upward particles transport stops in the present reactor and the particles remain in the base of the cone. Particles with a diameter larger than $200 \mu \mathrm{m}$ should not be used in our particular reactor because the heat penetration into the particle will not be sufficient to allow for conversion of the particle centre.

\section{CONCLUSIONS}

Measurements in the present rotating cone reactor, and calculations based on the experimental set-up led to the following conclusions,

-Particles larger than $400 \mu \mathrm{m}$ seem to be unaffected by the viscous forces because of their mass inertia, and the residence time of such particles is hardly dependent on the particle diameter.

-If the particle diameter is smaller than $200 \mu \mathrm{m}$ the viscous forces become important compared to the mass inertia and the particle residence time is strongly dependent on the particle diameter.

-At cone rotational frequencies of 5-30 s-1, the time-averaged particle Nusselt number for particles with a diameter of 140 or $250 \mu \mathrm{m}$ is expected to be approximately 4.

-If figure 9 is considered, particles smaller than $200 \mu \mathrm{m}$ can be completely converted if the cone rotational frequency is less than $15 \mathrm{~s}^{-1}$.

Future experiments will involve the analysis of the heat transfer to particles, and the pyrolysis of biomass particles.

\section{NOMENCLATURE}

$\begin{array}{ll}\text { C } & \text { concentration } \\ \mathrm{C}_{d} & \text { Drag coefficient } \\ \mathrm{C}_{\mathrm{p}} & \text { Heat capacity } \\ \mathrm{d}_{\mathrm{p}} & \text { Particle diameter } \\ \mathrm{E} & \text { Force } \\ \mathrm{g} & \text { Gravitational force per unit mass } \\ \mathrm{h} & \text { Surface roughness } \\ \mathrm{H}_{\mathrm{r}} & \text { Heat of reaction }\end{array}$

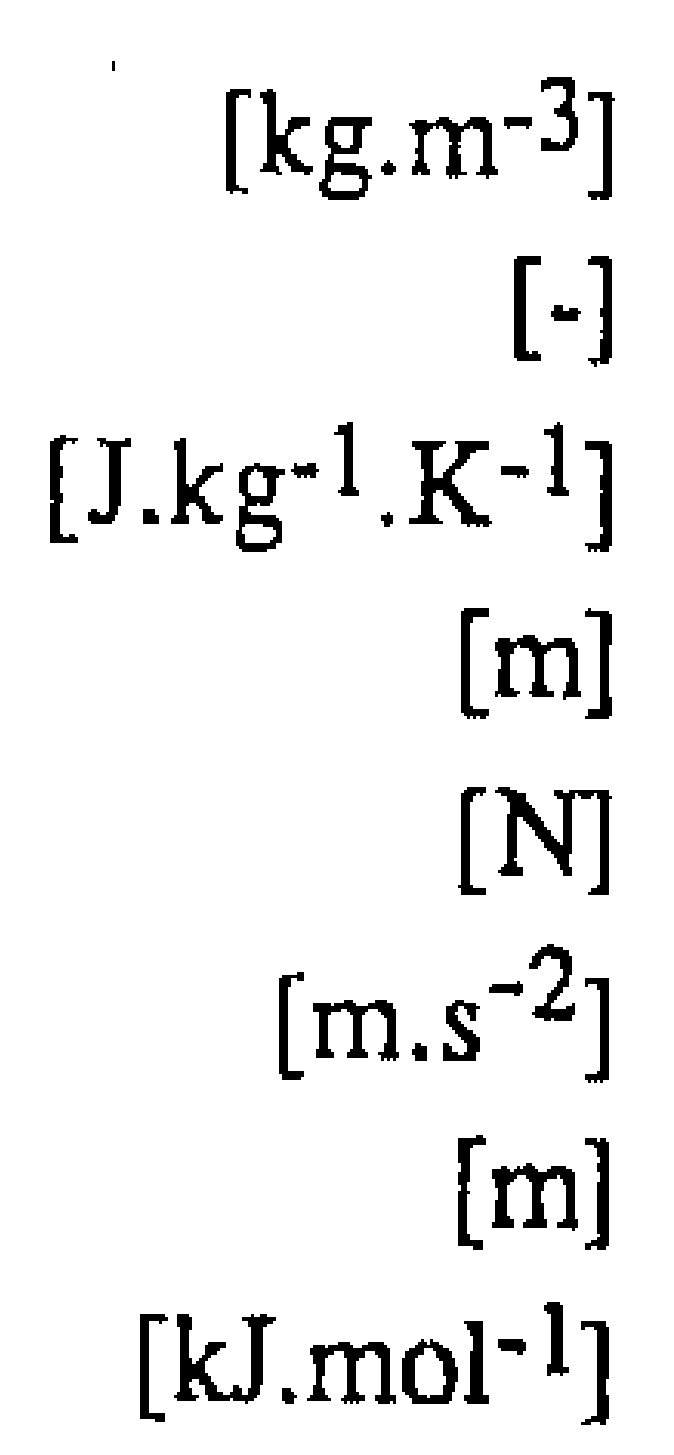




$\begin{array}{llr}\mathrm{k} & \text { Pre-exponential constant } & {\left[\mathrm{s}^{-1}\right]} \\ \mathrm{m}_{\mathrm{p}} & \text { Particle mass } & {[\mathrm{kg}]} \\ \mathrm{n} & \text { Cone rotational frequency } & {\left[\mathrm{s}^{-1}\right]} \\ \mathrm{n} & \text { Surface normal vector } & {[-]} \\ \mathrm{Nu} & \text { Nusselt number } & {[-]} \\ \mathrm{Pr} & \text { Prandlt number } & {[-]} \\ \mathrm{I} & \text { Radius, spherical co-ordinates } & {[\mathrm{m}]} \\ \mathrm{R} & \text { Radius, cylindrical co-ordinates } & {[\mathrm{m}]} \\ r & \text { Radius, particle co-ordinate } & {[\mathrm{m}]} \\ \mathrm{Re} & \text { Reynolds number } & {[-]} \\ \underline{\mathrm{y}} & \text { Velocity } & {\left[\mathrm{m} \cdot \mathrm{s}^{-1}\right]}\end{array}$

Greek symbols

$\alpha \quad$ External heat transfer coefficient $\left[\mathrm{W} \cdot \mathrm{m}^{-2} \cdot \mathrm{K}^{-1}\right]$

$\delta \quad$ Thickness of the logarithmic layer [m]

$\phi^{*} \quad$ Ultimate tar yield, weight\% $\quad[-]$

$\xi$ Wood conversion $[-]$

$\lambda$ Thermal conductivity $\quad\left[\mathrm{W} \cdot \mathrm{m}^{-1} \cdot \mathrm{K}^{-1}\right]$

$\rho$ Density $\left[\mathrm{kg} \cdot \mathrm{m}^{-3}\right]$

$\tau_{\mathrm{p}}$ Particle residence time [s]

$\omega$ Cone angular speed $\quad\left[\mathrm{rad} . \mathrm{s}^{-1}\right.$ ]

\begin{tabular}{ll}
\multicolumn{3}{l}{ Subscripts } \\
d & drag \\
f & fluid \\
g & gravity \\
p & particle \\
s & solid \\
w & wall \\
W & wood \\
0 & initial
\end{tabular}

Table 1. Parameters used.

\begin{tabular}{lrl}
\hline Gravitational constant g & 9.81 & {$\left[\mathrm{~m} \cdot \mathrm{s}^{-2}\right]$} \\
Fluid phase density $\rho_{\mathrm{f}}$ & 1.2 & {$\left[\mathrm{~kg} \cdot \mathrm{m}^{-3}\right]$} \\
Particle density $\rho_{\mathrm{p}}$ & 1100 & {$\left[\mathrm{~kg} \cdot \mathrm{m}^{-3}\right]$} \\
Surface roughness $\mathrm{h}$ & $0.5 .10^{-3}$ & {$[\mathrm{~m}]$} \\
Cone top angle & $\pi / 3$ & {$[\mathrm{rad}]$} \\
Cone height & 0.435 & {$[\mathrm{~m}]$} \\
Impeller radius & 0.072 & {$[\mathrm{~m}]$} \\
Fluid phase viscosity $\eta_{\mathrm{f}}$ & $1.8 .10^{-5}$ & {$[\mathrm{~Pa} \cdot \mathrm{s}]$} \\
Initial particle- & & \\
$\quad$ radial position $\mathrm{r}_{\mathrm{o}}$ & 0.071 & {$[\mathrm{~m}]$} \\
$\quad$ velocity $\mathrm{v}_{\phi, 0}$ & $\omega . \mathrm{r}_{\mathrm{o}}$ & {$\left[\mathrm{m} \cdot \mathrm{s}^{-1}\right]$} \\
$\quad$ wall distance & $10^{-3}$ & {$[\mathrm{~m}]$} \\
Heat capacity $\mathrm{C}_{\mathrm{p}, \mathrm{s}}$ & 1335 & {$\left[\mathrm{~J} \cdot \mathrm{kg}^{-1} \cdot \mathrm{K}^{-1}\right]$} \\
Thermal conductivity $\lambda_{\mathrm{s}}$ & 0.105 & {$\left[\mathrm{~W} \cdot \mathrm{m}^{-1} \cdot \mathrm{K}^{-1}\right]$} \\
Heat of the pyrolysis reaction $\mathrm{H}_{\mathrm{r}}$ & 500 & {$\left[\mathrm{~kJ} \cdot \mathrm{kg}^{-1}\right]$}
\end{tabular}




\section{REFERENCES}

1. Schlichting, $\mathrm{H}$.

Boundary layer theory.

McGraw-Hill, 1960, pp.519-33.

2. Lomas, C.G.

Fundamentals of hot wire anemometry.

Cambridge University Press, 1986.

3. Ranz, W.E. and Marshall, W.R.

Evaporation from drops, part II.

Chem. Eng. Progr., 1952, 48, 173-80.

4. Liden, A.G., Berruti, F. and Scott, D.S.

A kinetic model for the production of liquids from the flash pyrolysis of biomass.

Chem. Eng. Comm., 1988, 65, 207-21.

5. Kosstrin, $\mathrm{H}$.

Proc. Spec. Workshop on Fast Pyrolysis of Biomass,

Copper Mountain, Colorado, U.S.A, 1980, pp. 105-21.

6. Deglise, X., Richard, C., Rolin, A. and Francois, H.

Fast pyrolysis/gasification of lignocellulosic materials at short residence time.

Energy from biomass, 1st E.C. Conference,1980, pp. 548-53 